\title{
Aqueous paramagnetic solutions for MRI phantoms at 3 T: A detailed study on relaxivities
}

\author{
Kalaivani THANGAVEL ${ }^{1, *}$, Emine Ülkü SARITAŞ ${ }^{1,2,3}$ \\ ${ }^{1}$ National Magnetic Resonance Research Center (UMRAM), Bilkent University, Bilkent, Ankara, Turkey \\ ${ }^{2}$ Department of Electrical and Electronics Engineering, Bilkent University, Bilkent, Ankara, Turkey \\ ${ }^{3}$ Neuroscience Graduate Program, Bilkent University, Bilkent, Ankara, Turkey
}

\begin{tabular}{llll}
\hline Received: 09.02 .2016 & $\bullet$ & Accepted/Published Online: 18.08 .2016 & Final Version: 29.05 .2017 \\
\hline
\end{tabular}

\begin{abstract}
Phantoms with known $\mathrm{T}_{1}$ and $\mathrm{T}_{2}$ values that are prepared using solutions of easily accessible paramagnetic agents are commonly used in MRI imaging centers, especially with the goal of validating the accuracy of quantitative imaging protocols. The relaxivity parameters of several agents were comprehensively examined at lower $\mathrm{B}_{0}$ field strengths, but studies at $3 \mathrm{~T}$ remain limited. The main goal of this study is to measure $\mathrm{r}_{1}$ and $\mathrm{r}_{2}$ relaxivities of three common paramagnetic agents $\left(\mathrm{CuSO}_{4}, \mathrm{MnCl}_{2}\right.$, and $\left.\mathrm{NiCl}_{2}\right)$ at room temperature at $3 \mathrm{~T}$. Separate phantoms were prepared at various concentrations of $0.05-0.5 \mathrm{mM}$ for $\mathrm{MnCl}_{2}$ and 1-6 mM for $\mathrm{CuSO}_{4}$ and $\mathrm{NiCl}_{2}$. For assessment of $\mathrm{T}_{1}$ relaxation times, inversion recovery turbo spin echo images were acquired at 15 inversion times ranging between 24 and $2500 \mathrm{~ms}$. For assessment of $\mathrm{T}_{2}$ relaxation times, spin-echo images were acquired at 15 echo times ranging between 8.5 and $255 \mathrm{~ms}$. Voxel-wise $\mathrm{T}_{1}$ and $\mathrm{T}_{2}$ relaxation times at each concentration were separately determined from the respective signal recovery curves (inversion recovery for $T_{1}$ and spin echo decay for $T_{2}$ ). Relaxivities $r_{1}$ and $r_{2}$ for all three agents that were derived from these relaxation time measurements are reported: $\mathrm{r}_{1}=0.602 \mathrm{mM}^{-1} \mathrm{~s}^{-1}$ and $\mathrm{r}_{2}=$ $0.730 \mathrm{mM}^{-1} \mathrm{~s}^{-1}$ for $\mathrm{CuSO}_{4}, \mathrm{r}_{1}=6.397 \mathrm{mM}^{-1} \mathrm{~s}^{-1}$ and $\mathrm{r}_{2}=108.266 \mathrm{mM}^{-1} \mathrm{~s}^{-1}$ for $\mathrm{MnCl}_{2}, \mathrm{r}_{1}=0.620 \mathrm{mM}^{-1} \mathrm{~s}^{-1}$ and $\mathrm{r}_{2}=0.848 \mathrm{mM}^{-1} \mathrm{~s}^{-1}$ for $\mathrm{NiCl}_{2}$. These results will serve as a practical reference to design phantoms of target $\mathrm{T}_{1}$ and $\mathrm{T}_{2}$ values at $3 \mathrm{~T}$, in particular phantoms with relaxation times equivalent to specific human tissues.
\end{abstract}

Key words: $\mathrm{T}_{1}, \mathrm{~T}_{2}$, relaxivity, $3 \mathrm{~T}$ MRI, paramagnetic phantoms, quantitative imaging

\section{Introduction}

Quantitative magnetic resonance relaxometry is a surging field of interest in MRI. By determining the relaxation time constants, one can generate quantitative tissue maps in vivo, to help distinguish healthy tissue from pathology [1]. Quantitative relaxometry also serves a critical role in characterization of MRI contrast agents that shorten the longitudinal relaxation time $\left(\mathrm{T}_{1}\right)$ and/or the transversal relaxation time $\left(\mathrm{T}_{2}\right)[2-5]$. The efficacy of such contrast agents can be assessed via their relaxivities, i.e. the amount of shortening in $\mathrm{T}_{1}$ or $\mathrm{T}_{2}$ of nearby tissue per unit concentration of the agent. The reliability of these assessments depends on accurate quantification of relaxation time constants, typically necessitating prohibitively long scan times. Hence, improving the speed of $T_{1}$ and $T_{2}$ mapping sequences is an active area of research. With increased speed, however, one needs to ensure that the accuracy is not compromised. Therefore, it is desirable to validate the accuracy of the quantitative imaging protocols a priori on phantoms with known $\mathrm{T}_{1}$ and $\mathrm{T}_{2}$ values.

*Correspondence: kalaivani@bilkent.edu.tr 
THANGAVEL and SARITAŞ/Turk J Elec Eng \& Comp Sci

Several paramagnetic contrast agents are frequently utilized by NMR/MRI researchers to prepare phantoms with desired $T_{1}$ and $T_{2}$ values, for example to mimic the $T_{1} / T_{2}$ of white matter tissue [6]. Among these agents are copper sulfate $\left(\mathrm{CuSO}_{4}\right)$, nickel chloride $\left(\mathrm{NiCl}_{2}\right)$, and manganese chloride $\left(\mathrm{MnCl}_{2}\right)$ [6-10], which are used due to their water-solubility, high stability, homogeneity, and the ease of preparing phantoms with relaxation times within the typical range for biological tissue $[11,12]$. The relaxivities of these agents were reported previously at low field strengths $(0.5 \mathrm{~T}$ to $1.5 \mathrm{~T})$, and these reports serve as a useful reference in preparation of phantoms with desired $\mathrm{T}_{1} / \mathrm{T}_{2}$ values. However, relaxivity parameters are known to show strong dependency on $\mathrm{B}_{0}$ field strength $[13,14]$. With $3 \mathrm{~T}$ MRI scanners being extensively used in the clinic and in research settings [14-17], there is a pressing need for comprehensive relaxivity assessments at $3 \mathrm{~T}$. A recent study looked at developing 3 T MRI phantoms that are similar to human tissues in terms of their relaxation times and conductivities [18]. The phantoms in that previous study were prepared using agarose, gadolinium chloride $\left(\mathrm{GdCl}_{3}\right)$, and sodium chloride $(\mathrm{NaCl})$. Although Gd-based agents are gaining popularity [19-23], $\mathrm{CuSO}_{4}, \mathrm{MnCl}_{2}$, and $\mathrm{NiCl}_{2}$ remain the most commonly used paramagnetic agents for making imaging phantoms [24-27]. However, except for a few studies on $\mathrm{MnCl}_{2}$, the relaxivities for these agents have not yet been reported at $3 \mathrm{~T}$.

Here, we measure and report the longitudinal $\left(\mathrm{r}_{1}\right)$ and transversal $\left(\mathrm{r}_{2}\right)$ relaxivities of three different paramagnetic solutions, $\mathrm{CuSO}_{4}, \mathrm{MnCl}_{2}$, and $\mathrm{NiCl}_{2}$, at room temperature at $3 \mathrm{~T}$. First, $\mathrm{T}_{1}$ - and $\mathrm{T}_{2}$-weighted images are acquired for all three paramagnetic agents at various concentrations. The longitudinal $\left(\mathrm{T}_{1}\right)$ and transverse $\left(\mathrm{T}_{2}\right)$ relaxation times are obtained respectively from the exponential inversion-recovery and echodecay curves. $\mathrm{T}_{1}$ fitting is performed using two different models: a conventional two-parameter model and a three-parameter model [28], which was recently shown to be more robust against $\mathrm{B}_{1}$ inhomogeneities. The inverses of the relaxation times $\left(1 / \mathrm{T}_{1}\right.$ and $\left.1 / \mathrm{T}_{2}\right)$ of all three paramagnetic phantoms are found to be linear with concentration $\left(\mathrm{r}^{2}>0.997\right)$. Furthermore, the three-parameter model significantly outperformed the twoparameter model based on a leave-five-out (L5O) cross-validation procedure $(\mathrm{P}<0.001$, paired Wilcoxon signed-rank test). Our results can serve as a practical reference for phantom design and for calibration of quantitative MRI imaging/analysis protocols at $3 \mathrm{~T}$.

\section{Theory}

MRI image contrast can be greatly enhanced by exogenous contrast agents that significantly alter intrinsic $\mathrm{T}_{1}$ and $\mathrm{T}_{2}$ relaxation times of biological tissues. The relaxation times in the presence of such contrast agents can be approximated by:

$$
\begin{aligned}
& \frac{1}{T_{1}}=\frac{1}{T_{1, d i a}}+r_{1} \cdot C \\
& \frac{1}{T_{2}}=\frac{1}{T_{2, d i a}}+r_{2} \cdot C,
\end{aligned}
$$

where the subscript 'dia' refers to diamagnetic host solution (water in our case), $\mathrm{C}[\mathrm{mM}]$ is the concentration of the contrast agent, and $\mathrm{r}_{1}\left[\mathrm{mM}^{-1} \mathrm{~s}^{-1}\right]$ and $\mathrm{r}_{2}\left[\mathrm{mM}^{-1} \mathrm{~s}^{-1}\right]$ are the longitudinal and transverse relaxivities that reflect the efficiency of the agent. Here, the reciprocals of the relaxation times, $R_{1}=1 / T_{1}\left[s^{-1}\right]$ and $R_{2}$ $=1 / \mathrm{T}_{2}\left[\mathrm{~s}^{-1}\right]$, are called the concentration-dependent relaxation rates.

Various standard techniques are available for estimating relaxation time constants, such as inversion recovery (IR), look-locker (LL), saturation recovery (SR), or variable flip angle (VFA) method for $\mathrm{T}_{1}$ mapping 
THANGAVEL and SARITAŞ/Turk J Elec Eng \& Comp Sci

[29], and Carr-Purcell-Meiboom-Gill (CPMG) multi-echo or single-echo spin echo (SE) sequences for $\mathrm{T}_{2}$ mapping [30]. The optimal choice of relaxometry technique depends on the signal intensity, available scan time, and the required accuracy and precision for the estimation. Here we used the most common techniques for $\mathrm{T}_{1}$ and $\mathrm{T}_{2}$ mapping, IR and $\mathrm{SE}$ sequences, respectively.

In the IR sequence, the net magnetization is initially inverted by applying a $180^{\circ} \mathrm{RF}$ pulse. The magnetization is allowed to recover during a wait time called the inversion time (TI), which is followed by a $90^{\circ}$ excitation RF pulse and data acquisition. Separate image acquisitions are performed at a range of distinct TI values. The conventional two-parameter signal model is then given by [25]

$$
S=S_{0}\left[1-2 e^{-\frac{T I}{T_{1}}}+e^{-\frac{T R}{T_{1}}}\right]
$$

where $\mathrm{TR}$ is the repetition time and $\mathrm{S}_{0}$ is the signal amplitude after full magnetization recovery. Here the two parameters to be fitted to the acquired data are $\mathrm{S}_{0}$ and $\mathrm{T}_{1}$. This idealized model assumes an exact $180^{\circ}$ inversion pulse, which is rarely the case, as the effective flip angle depends on $\mathrm{B}_{1}$ field uniformity, as well as $\mathrm{T}_{1}$ and $\mathrm{T}_{2}$ [31]. A recent study provided a more accurate model for the IR signal [32]:

$$
S=S_{1}+S_{2} e^{-\frac{T I}{T_{1}}}
$$

Here $\mathrm{S}_{1}$ and $\mathrm{S}_{2}$ can be seen as two separate components of the received signal: $\mathrm{S}_{1}$ is the signal without any inversion pulses and $\mathrm{S}_{2}$ stems from the inverted magnetization. Both $\mathrm{S}_{1}$ and $\mathrm{S}_{2}$ are complex valued, with $\mathrm{S}_{2}$ having a $180^{\circ}$ phase offset with respect to $S_{1}$. When magnitude images (as opposed to complex MRI data) are utilized, $\mathrm{S}_{1}$ and $\mathrm{S}_{2}$ can be treated as real-valued parameters. In this case, $\mathrm{S}_{1}$ will be positive valued and $\mathrm{S}_{2}$ negative valued (see the Data analysis section for details on the extraction of signal positivity/negativity from magnitude images). Hence, the signal equation reduces to a three-parameter model, with the parameters $\mathrm{S}_{1}$, $\mathrm{S}_{2}$, and $\mathrm{T}_{1}$. Note that this model does not assume a perfect inversion pulse and it does not require $\mathrm{TR}>>$ $\mathrm{T}_{1}$. In this work, the $\mathrm{T}_{1}$ mapping was performed via both the two- and the three-parameter models (Eqs. (3) and (4)), and the results were compared.

In the $\mathrm{SE}$ sequence that is used for $\mathrm{T}_{2}$ mapping, a $90^{\circ}$ excitation $\mathrm{RF}$ pulse flips the magnetization into the transverse plane. Any potential dephasing of the signal due to $\mathrm{B}_{0}$ field inhomogeneity or chemical shift is corrected by applying a refocusing $180^{\circ} \mathrm{RF}$ pulse, followed by data acquisition at an echo time TE. Separate images are acquired at a range of distinct TE values. Assuming a monoexponential decay, the corresponding time constant $\mathrm{T}_{2}$ is determined by

$$
S=S_{0} e^{-\frac{T E}{T_{2}}},
$$

where $\mathrm{S}_{0}$ is signal amplitude without $\mathrm{T}_{2}$ decay. Here the parameters to be fitted are $\mathrm{S}_{0}$ and $\mathrm{T}_{2}$.

\section{Materials and methods \\ 3.1. Phantom preparation}

Separate phantoms of manganese chloride $\left(\mathrm{MnCl}_{2}\right)$, copper sulfate $\left(\mathrm{CuSO}_{4}\right)$, and nickel chloride $\left(\mathrm{NiCl}_{2}\right)$ were prepared at 6 different concentrations, each with a total volume of $50 \mathrm{~mL} . \mathrm{MnCl}_{2}$ solutions varying between 0.05 and $0.5 \mathrm{mM}$ concentration were prepared by dissolving anhydrous manganese chloride $(99 \%$ purity, Sigma Aldrich) in double distilled water. Similarly, $\mathrm{CuSO}_{4}$ and $\mathrm{NiCl}_{2}$ solutions varying between 1 and $6 \mathrm{mM}$ concentration were prepared by dissolving copper sulfate pentahydrate $\left(\mathrm{CuSO}_{4} .5 \mathrm{H}_{2} \mathrm{O}, 98 \%\right.$ purity, 
THANGAVEL and SARITAŞ/Turk J Elec Eng \& Comp Sci

Merck) and nickel chloride hexahydrate $\left(\mathrm{NiCl}_{2} \cdot 6 \mathrm{H}_{2} \mathrm{O},>97 \%\right.$ purity, Merck) in double distilled water. The concentrations were chosen to obtain similar ranges of $\mathrm{T}_{1}$ values for all three paramagnetic agents (determined after preliminary MRI measurements, not shown) that were in the relevant range for biological tissue without [33] and with contrast injection [34] at $3 \mathrm{~T}$. All solutions were prepared in sterilized polypropylene centrifuge tubes of 3 -cm diameter and 12-cm length. Because $\mathrm{T}_{1}$ and $\mathrm{T}_{2}$ of pure water (approximately $5000 \mathrm{~ms}$ and $3200 \mathrm{~ms}$, respectively [21]) is significantly higher than $\mathrm{T}_{1} / \mathrm{T}_{2}$ of these paramagnetic solutions, a pure water phantom was not included during MRI experiments (similar to previous studies such as [8,10,35-37]). Including pure water would require TR to be at least 3-4 times higher than the currently used value (section 3.2, MRI studies), which in turn would significantly prolong the imaging time.

\subsection{MRI studies}

Image acquisition was performed on a $3 \mathrm{~T}$ MRI scanner (Siemens Magnetom, maximum gradient strength of $45 \mathrm{mT} / \mathrm{m}$ and slew rate of $200 \mathrm{~T} / \mathrm{m} / \mathrm{s}$ ) using a 32-channel receive-only head coil. For each paramagnetic agent, solutions prepared at 6 different concentrations were imaged concurrently (see Figures 1 and 2). The imaging parameters such as TR and the ranges of TI and TE were chosen to match the previous relaxivity study on $\mathrm{MnCl}_{2}$ at $3 \mathrm{~T}$ [25], to enable a direct comparison of the results. The numbers of TIs and TEs were chosen based on preliminary experiments (results not shown) to give reliable $r_{1}$ and $r_{2}$ estimates. $T_{1}$ relaxation times were measured with an IR turbo spin echo sequence and $\mathrm{TR}=3000 \mathrm{~ms}$ to allow for near-full recovery of magnetization. Images were acquired at 15 different $\mathrm{TI}=[24,50,100,150,200,250,500,750,1000,1250$, $1500,1750,2000,2250,2500] \mathrm{ms}$, with a total scan time of $2 \mathrm{~min} 41 \mathrm{~s}$ per image. A minimum TE $=12 \mathrm{~ms}$ and an acquisition matrix of $256 \times 256$ were prescribed. $\mathrm{T}_{2}$ relaxation times were measured with a single-echo $\mathrm{SE}$ sequence with $\mathrm{TR}=2000 \mathrm{~ms}$. Images were acquired at 15 different $\mathrm{TE}=[8.5,15,25,35,55,75,95,115$, $135,155,175,195,215,235,255] \mathrm{ms}$, with a total scan time of $3 \mathrm{~min} 30 \mathrm{~s}$ per image. An acquisition matrix of $128 \times 102$ (i.e. $80 \%$ phase-FOV) was prescribed, and the final image was reconstructed with a matrix size of $256 \times 256$. The remaining parameters were kept identical for both sequences: $4 \mathrm{~mm}$ slice thickness, $90^{\circ}$ flip angle, and $12 \mathrm{~cm} \times 12 \mathrm{~cm}$ field-of-view (FOV). Individual-coil images were sensitivity weighted and then linearly combined $[38,39]$.

\subsection{Data analysis}

The MRI data were analyzed using an in-house script developed in MATLAB (MathWorks, Natick, MA, USA). For $\mathrm{T}_{1}$ mapping, both two-parameter and three-parameter models were implemented. The reason for this choice was that, while it has been shown that the two-parameter model does not work well under $\mathrm{B}_{1}$ field nonuniformity [28,32], it remains the most commonly used $\mathrm{T}_{1}$ mapping method.

For each phantom, a circular region of interest (ROI) was chosen manually. Then pixel-wise $\mathrm{T}_{1}$ values were determined in the selected ROIs (1214 \pm 124 pixels per ROI), first using the two-parameter model in Eq. (3). For magnitude MRI images, the sign of the signal S in Eq. (3) is not immediately available. To determine the sign, one first needs to determine the zero-crossing point of the inversion recovery curve (i.e. the TI for which the signal is zero). Hence, we first found the TI value, $\mathrm{TI}^{*}$, for which the voxel at hand had the minimum absolute signal level. Then, for all the TI values smaller than $\mathrm{TI}^{*}$, the sign of the signal was flipped. One cannot directly conclude whether the sign of the signal at TI* should also be flipped. Therefore, two different fittings were done: one where the signal at $\mathrm{TI}^{*}$ remained positive valued and one where its sign was flipped. 

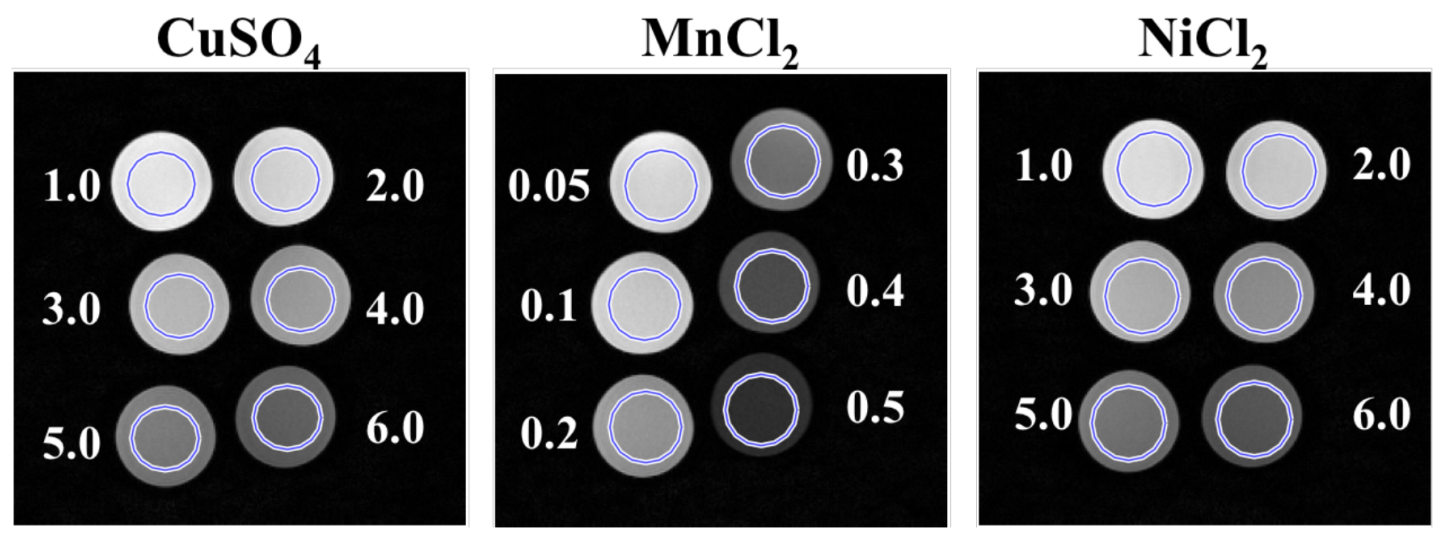

Figure 1. Example inversion recovery (IR) turbo spin echo images (acquired with TI = $100 \mathrm{~ms}$ ) for all three paramagnetic solutions, showing the selected regions of interest (ROIs). The concentration for each phantom is denoted in units of mM. For each phantom, the $\mathrm{T}_{1}$ values are determined in the selected circular ROI (1214 \pm 124 pixels per ROI). For this example image, $\mathrm{TI}=100 \mathrm{~ms}$ corresponds to a time point before the zero crossing of the magnetization recovery curves for all samples. Hence, a lower signal level in the image denotes faster $\mathrm{T}_{1}$ relaxation. Other imaging parameters were $\mathrm{TR}=3000 \mathrm{~ms}, \mathrm{TE}=12 \mathrm{~ms}, 4 \mathrm{~mm}$ slice thickness, $90^{\circ}$ flip angle, and $12 \mathrm{~cm} \times 12 \mathrm{~cm}$ field-of-view (FOV).
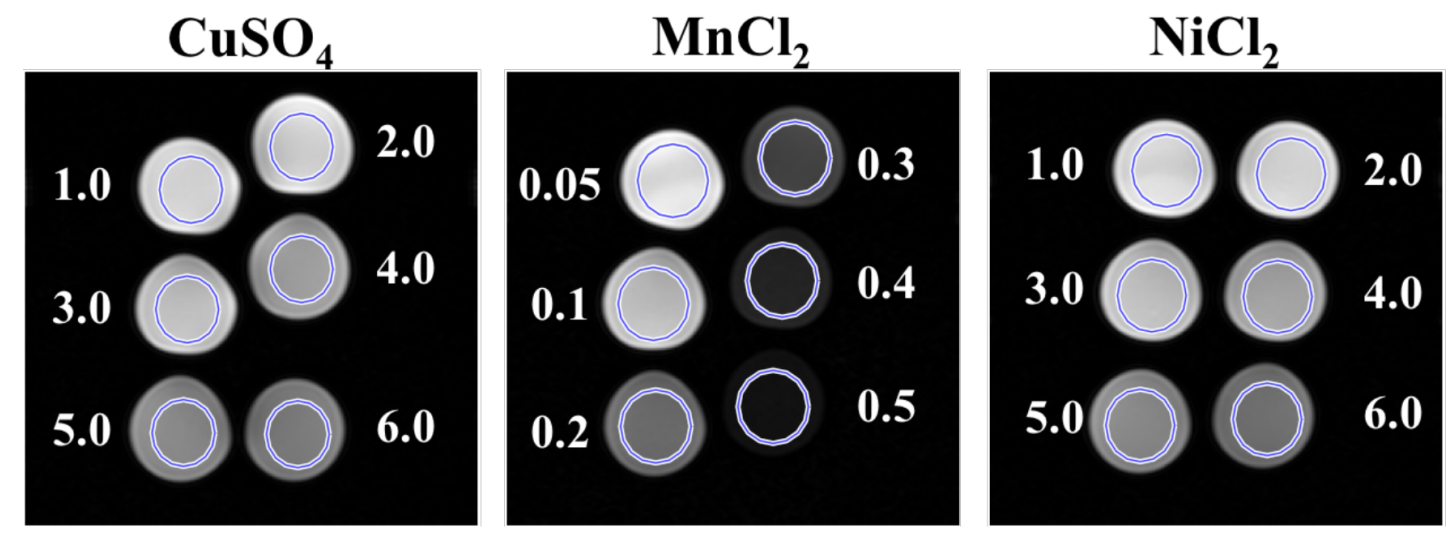

Figure 2. Example spin echo (SE) images (acquired with $\mathrm{TE}=155 \mathrm{~ms}$ for $\mathrm{CuSO}_{4}$ and $\mathrm{NiCl}_{2}$, and with $\mathrm{TE}=55 \mathrm{~ms}$ for $\mathrm{MnCl}_{2}$ ) for all three paramagnetic solutions, showing the selected regions of interest (ROIs). The concentration for each phantom is denoted in units of $\mathrm{mM}$. For each phantom, the $\mathrm{T}_{2}$ values are determined in the selected circular ROI $(1214 \pm 124$ pixels per ROI). In all three images, the signal level is lower for higher concentrations of paramagnetic ions, corresponding to faster $\mathrm{T}_{2}$ relaxation. Other imaging parameters were $\mathrm{TR}=2000 \mathrm{~ms}, 4 \mathrm{~mm}$ slice thickness, $90^{\circ}$ flip angle, and $12 \mathrm{~cm} \times 12 \mathrm{~cm}$ field-of-view (FOV).

Levenberg-Marquardt nonlinear least squares regression was performed on the resulting two data sets using Eq. (3). These two cases were then compared via the root mean square errors (RMSEs) of the fits and the one with the smaller RMSE was determined to be the correct case [32].

Next, the mean and standard deviation values for all pixels within the ROI were calculated. $\mathrm{R}_{1}$ relaxation rate (i.e. $1 / \mathrm{T}_{1}$ ) was then plotted as a function of concentration of the paramagnetic phantoms (i.e. with $1214 \pm$ 124 points at each of six different concentration levels). Finally, the longitudinal relaxivity $\left(\mathrm{r}_{1}\right)$ was calculated via linear least squares regression on this plot. This entire procedure was repeated for the three-parameter model for $\mathrm{T}_{1}$ mapping, using Eq. (4). The goodness-of-fit for the two-parameter vs. the three-parameter models was evaluated using the adjusted $\mathrm{R}^{2}$ metric, and the results were compared via a paired Wilcoxon signed-rank test. 
THANGAVEL and SARITAŞ/Turk J Elec Eng \& Comp Sci

One concern when using more parameters in a model is overfitting of the data [40]. To ensure that this was not the case with the three-parameter model, model performance was estimated via leave-five-out (L5O) cross-validation [41-43]. While the fact that the three-parameter model remains more robust under $\mathrm{B}_{1}$ field inhomogeneities has been shown previously [28,32], a statistical confirmation that it does not overfit the data was not shown before. Accordingly, out of the 15 TI values, every third TI was removed from the data set (i.e. validation set had 5 TI values). The remaining $10 \mathrm{TI}$ values acted as the training set for data fitting. The signal levels for the validation set were then estimated from the fitting results and compared with their actual values. This procedure was repeated three times by varying the validation set. The cross-validation results were evaluated using the adjusted $\mathrm{R}^{2}$ goodness-of-fit metric for both two-parameter and three-parameter models, and the results were compared via a paired Wilcoxon signed-rank test.

For $\mathrm{T}_{2}$ measurements, a similar procedure was repeated using Eq. (5) (without the sign reversal step). The resulting mean and standard deviation values for $\mathrm{R}_{2}$ relaxation rate (i.e. $1 / \mathrm{T}_{2}$ ) were plotted as a function of concentration and the transversal relaxivity $\left(\mathrm{r}_{2}\right)$ was calculated.

\section{Results}

In Figure 1, example inversion recovery images with $\mathrm{TI}=100 \mathrm{~ms}$ are shown for all three samples. The particular TI value shown in Figure 1 corresponds to a point before the zero crossing of the magnetization recovery curves for all samples, so that a lower signal level in the image corresponds to a faster $\mathrm{T}_{1}$ relaxation, which in turn corresponds to higher concentrations of the paramagnetic phantoms. Similarly, example spin-echo images for all three samples are given in Figure 2. As expected, the signal level is lower for higher concentrations of the paramagnetic phantoms, corresponding to faster $\mathrm{T}_{2}$ relaxation.

The pixel-wise $T_{1}$ values were determined in the selected ROIs, and the measured signal intensities were fitted using Eqs. (3) and (4). The adjusted $\mathrm{R}^{2}$ goodness-of-fit metric for the three-parameter model was found to be significantly higher $(\mathrm{P}<0.001$, paired Wilcoxon signed-rank test) than that of the two-parameter model. To visually show the difference between the two models, $\mathrm{T}_{1}$ color map and adjusted $\mathrm{R}^{2}$ color map for both models were computed for the $\mathrm{MnCl}_{2}$ phantoms, as shown in Figure 3 . As seen in this figure, the three-parameter model displays uniformly higher levels of adjusted $\mathrm{R}^{2}$, all very close to the ideal value of one. In fact, the adjusted $\mathrm{R}^{2}$ values for the three-parameter model were higher for all pixels in the ROIs (1214 \pm 124 pixels per phantom, and a total of 18 phantoms for all three paramagnetic solutions), indicating a better fit to the data points.

Next, we selected the pixel where the difference between the adjusted $\mathrm{R}^{2}$ values between the two models was the maximum. Figures $4 \mathrm{~A}$ and $4 \mathrm{~B}$ show the measured signal intensities as a function of TI for that pixel (in $0.5 \mathrm{mM} \mathrm{MnCl} 2$ phantom), with fitted $\mathrm{T}_{1}$ magnetization recovery curves overlaid. The two-parameter fit gave $\mathrm{T}_{1}=248.5 \mathrm{~ms}$ with adjusted $\mathrm{R}^{2}=0.9922$, whereas the three-parameter fit gave $\mathrm{T}_{1}=298.7$ ms with adjusted $\mathrm{R}^{2}=0.9996$. Upon closer inspection of the fitted curves, one can see that the two-parameter fit deviates from the data points at low and high TI values. The three-parameter fit, on the other hand, provides a much better agreement with the data points. Similar behavior was observed at other concentrations of $\mathrm{MnCl}_{2}(\mathrm{not}$ shown). To overrule the possibility that the three-parameter model overfits the data points, L5O cross-validation was performed, where the three-parameter model outperformed the two-parameter model $(\mathrm{P}<0.001$, paired Wilcoxon signed-rank test). Hence, we conclude that the three-parameter model provides a more accurate representation of the inversion recovery curve, which could stem from its robustness against nonideal inversion $\mathrm{RF}$ pulse resulting from $\mathrm{B}_{1}$ inhomogeneity. 

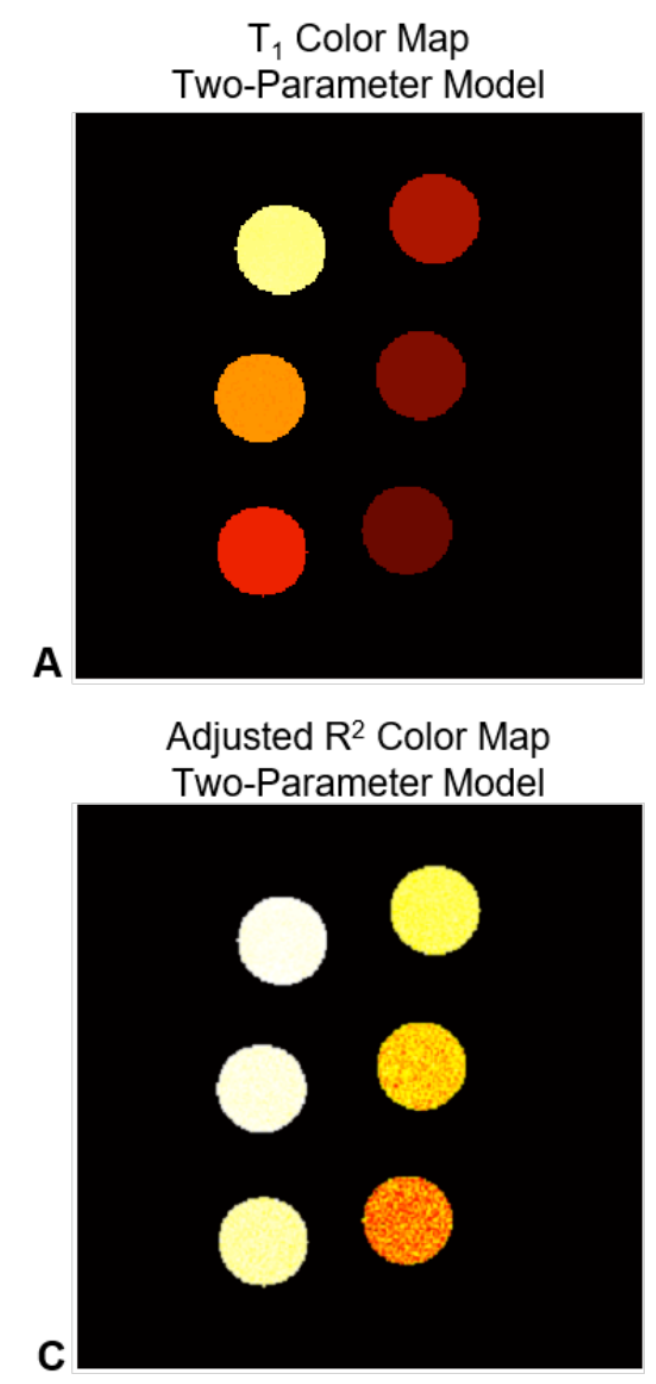
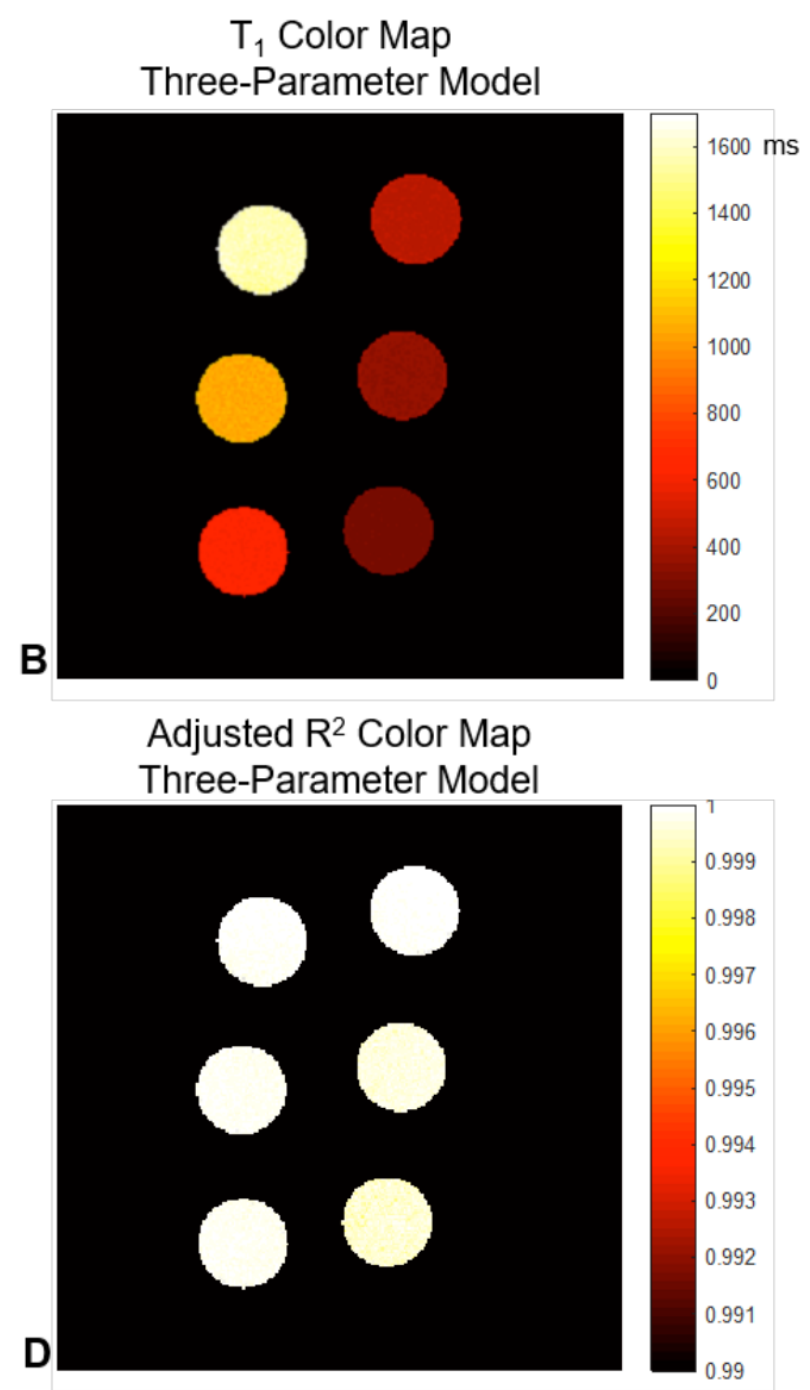

Figure 3. $\mathrm{T}_{1}$ and adjusted $\mathrm{R}^{2}$ color map comparisons for two- and three-parameter models for $\mathrm{MnCl}_{2}$ phantom. For $\mathrm{MnCl}_{2}$, (A) the two-parameter model slightly underestimates the $\mathrm{T}_{1}$ values when compared to (B) the three-parameter model. The adjusted $\mathrm{R}^{2}$ performance of $(\mathrm{C})$ the two-parameter model gets worse for lower $\mathrm{T}_{1}$ values. (D) The threeparameter model, on the other hand, has uniformly higher levels of adjusted $\mathrm{R}^{2}$ values, all very close to the ideal value of one. Note that in this figure, $\mathrm{T}_{1}$ and adjusted $\mathrm{R}^{2}$ values are computed on a pixel-by-pixel basis, only for the pixels in the selected circular ROIs (see Figure 1). Also note that (A-B) share the same color scale and (C-D) share the same color scale to enable a direct visual comparison.

Figure $4 \mathrm{C}$ shows an example of the fitting for the $\mathrm{T}_{2}$ signal decay curve. The measured signal intensities as a function of $\mathrm{TE}$ are plotted for a single pixel of the $0.05 \mathrm{mM} \mathrm{MnCl}_{2}$ phantom. The resulting $\mathrm{T}_{2}$ was $158.8 \mathrm{~ms}$ with adjusted $\mathrm{R}^{2}=0.9999$, and the fitted curve agreed well with the measurements. The obtained mean values of $\mathrm{T}_{1}$ and $\mathrm{T}_{2}$ for all three paramagnetic ions for varying concentrations, along with their standard deviations, are tabulated in Table 1.

The relaxation rates $R_{1}=1 / T_{1}$ and $R_{2}=1 / T_{2}$ are plotted as a function of concentration for all three paramagnetic solutions in Figures 5 and 6 , respectively. The error bars denote the mean and standard 

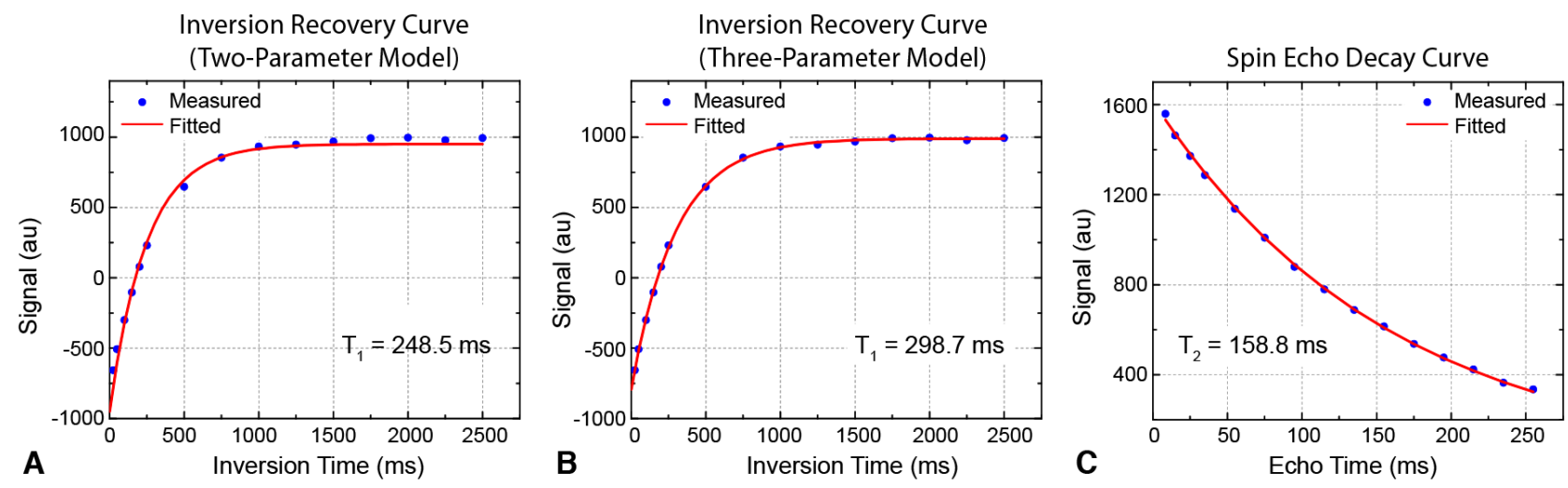

Figure 4. Inversion recovery curve for a single pixel of the $0.5 \mathrm{mM} \mathrm{MnCl} 2$ phantom fitted using (A) the two-parameter model (Eq. (3)) and (B) the three-parameter model (Eq. (4)). The two-parameter model gives $\mathrm{T}_{1}=248.5 \mathrm{~ms}$ with adjusted $\mathrm{R}^{2}=0.9922$, while the three-parameter model gives $\mathrm{T}_{1}=298.7 \mathrm{~ms}$ with adjusted $\mathrm{R}^{2}=0.9996$. The twoparameter fit deviates from the data points at low and high TI values, while the three-parameter fit shows a much better agreement. (C) Spin echo signal decay curve for a single pixel of the $0.05 \mathrm{mM} \mathrm{MnCl} 2$ phantom. The fitted curve has $\mathrm{T}_{2}=158.8 \mathrm{~ms}$ with adjusted $\mathrm{R}^{2}=0.9999$.

Table 1. The $\mathrm{T}_{1}$ and $\mathrm{T}_{2}$ relaxation times of $\mathrm{CuSO}_{4}, \mathrm{MnCl}_{2}$, and $\mathrm{NiCl}_{2}$ measured at $3 \mathrm{~T}$ for various concentrations. The mean values and standard deviations are given for each selected ROI (1214 \pm 124 pixels per ROI). The $\mathrm{T}_{1}$ values are reported for both the two-parameter and the three-parameter model as shown in Eqs. (3) and (4), respectively.

\begin{tabular}{|c|c|c|c|c|c|c|}
\hline \multirow{2}{*}{$\mathrm{CuSO}_{4}$} & \multicolumn{6}{|c|}{ Concentration (mM) } \\
\hline & 1.0 & 2.0 & 3.0 & 4.0 & 5.0 & 6.0 \\
\hline $\begin{array}{l}\mathrm{T}_{1}(\mathrm{~ms}) \\
\text { 2-Parameter Model }\end{array}$ & $1115.7 \pm 7.2$ & $679.9 \pm 3.3$ & $485.5 \pm 2.22$ & $376.7 \pm 1.66$ & $308.3 \pm 1.55$ & $261.0 \pm 1.22$ \\
\hline $\begin{array}{l}\mathrm{T}_{1}(\mathrm{~ms}) \\
\text { 3-Parameter Model }\end{array}$ & $1135.1 \pm 15.0$ & $681.8 \pm 6.2$ & $484.5 \pm 4.2$ & $373.5 \pm 2.7$ & $305.3 \pm 2.9$ & $257.1 \pm 2.1$ \\
\hline $\mathrm{T}_{2}(\mathrm{~ms})$ & $894.9 \pm 32.5$ & $549.4 \pm 11.6$ & $399.2 \pm 7.1$ & $304.2 \pm 3.4$ & $246.7 \pm 6.4$ & $211.4 \pm 1.8$ \\
\hline \multirow{2}{*}{$\mathrm{MnCl}_{2}$} & \multicolumn{6}{|c|}{ Concentration (mM) } \\
\hline & 0.05 & 0.1 & 0.2 & 0.3 & 0.4 & 0.5 \\
\hline $\begin{array}{l}\mathrm{T}_{1}(\mathrm{~ms}) \\
\text { 2-Parameter Model }\end{array}$ & $1481.8 \pm 12.9$ & $990.2 \pm 6.8$ & $571.5 \pm 3.5$ & $407.3 \pm 2.1$ & $309.0 \pm 2.6$ & $248.2 \pm 2.4$ \\
\hline $\begin{array}{l}\mathrm{T}_{1}(\mathrm{~ms}) \\
\text { 3-Parameter Model }\end{array}$ & $1561.3 \pm 28.6$ & $1046.5 \pm 16.4$ & $616.9 \pm 7.6$ & $448.7 \pm 3.8$ & $348.1 \pm 5.1$ & $283.6 \pm 4.8$ \\
\hline $\mathrm{T}_{2}(\mathrm{~ms})$ & $163.5 \pm 2.6$ & $88.4 \pm 0.3$ & $44.5 \pm 0.2$ & $30.5 \pm 0.1$ & $22.8 \pm 0.1$ & $18.2 \pm 0.1$ \\
\hline \multirow{2}{*}{$\mathrm{NiCl}_{2}$} & \multicolumn{6}{|c|}{ Concentration (mM) } \\
\hline & 1.0 & 2.0 & 3.0 & 4.0 & 5.0 & 6.0 \\
\hline $\begin{array}{l}\mathrm{T}_{1}(\mathrm{~ms}) \\
\text { 2-Parameter Model }\end{array}$ & $1067.5 \pm 5.6$ & $643.6 \pm 3.6$ & $463.7 \pm 1.8$ & $360.3 \pm 2.8$ & $297.2 \pm 1.3$ & $250.7 \pm 1.2$ \\
\hline $\begin{array}{l}\mathrm{T}_{1}(\mathrm{~ms}) \\
\text { 3-Parameter Model }\end{array}$ & $1082.0 \pm 13.2$ & $645.7 \pm 7.3$ & $463.3 \pm 3.4$ & $357.4 \pm 4.2$ & $295.7 \pm 2.2$ & $247.7 \pm 1.9$ \\
\hline $\mathrm{T}_{2}(\mathrm{~ms})$ & $743.6 \pm 17.6$ & $474.1 \pm 6.8$ & $336.9 \pm 6.5$ & $262.0 \pm 3.2$ & $214.1 \pm 2.8$ & $179.3 \pm 1.7$ \\
\hline
\end{tabular}

deviation among all pixels in the ROI for a given concentration of a sample. The results of the linear least square regressions are shown with red solid lines in Figures 5 and 6 , where the slopes correspond to $\mathrm{r}_{1}$ and $\mathrm{r}_{2}$ 
relaxivities $\left(\mathrm{r}^{2}>0.997\right.$ for all fitted lines). These relaxivity values are listed in Table 2 for all three paramagnetic ions, along with their $95 \%$ confidence intervals.
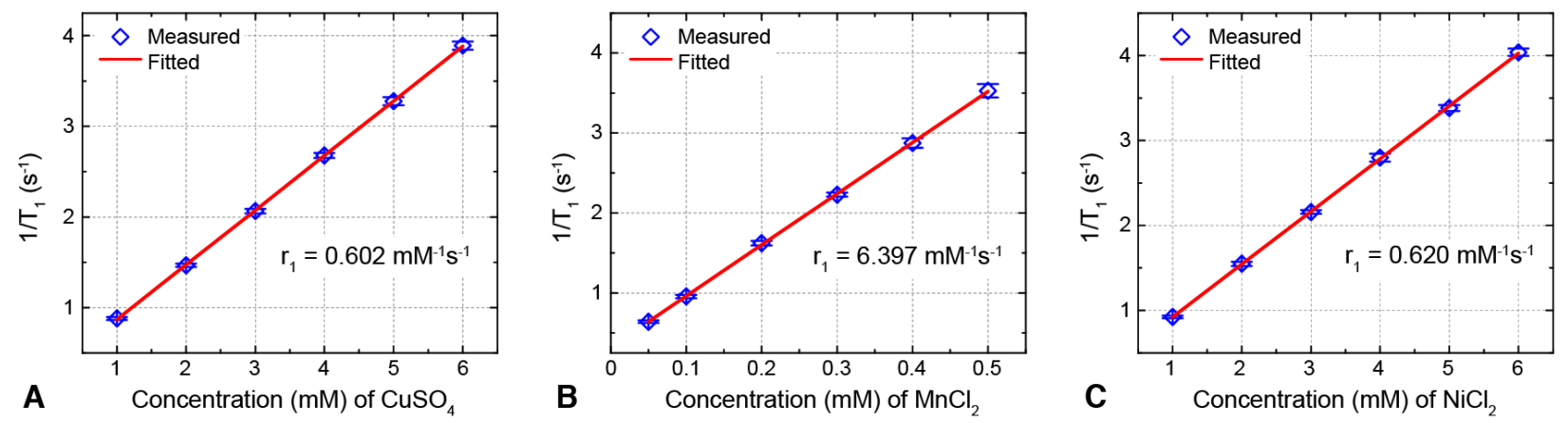

Figure 5. Longitudinal relaxation rates $\left(R_{1}=1 / T_{1}\right)$ as a function of concentration for all three paramagnetic solutions, fitted using the three-parameter model. The slopes of the fitted lines correspond to the $\mathrm{r}_{1}$ relaxivities: $(\mathrm{A}) \mathrm{r}_{1}=0.602$ $\mathrm{mM}^{-1} \mathrm{~s}^{-1}$ for $\mathrm{CuSO}_{4}$, (B) $\mathrm{r}_{1}=6.397 \mathrm{mM}^{-1} \mathrm{~s}^{-1}$ for $\mathrm{MnCl}_{2}$, and (C) $\mathrm{r}_{1}=0.620 \mathrm{mM}^{-1} \mathrm{~s}^{-1}$ for NiCl $\mathrm{N}_{2}$. The error bars show the mean and standard deviations of the relaxation rates for each selected ROI at the given concentration $\left(1214 \pm 124\right.$ pixels per ROI), and the solid red lines denote the linear least squares regressions with $r^{2}>0.999$.
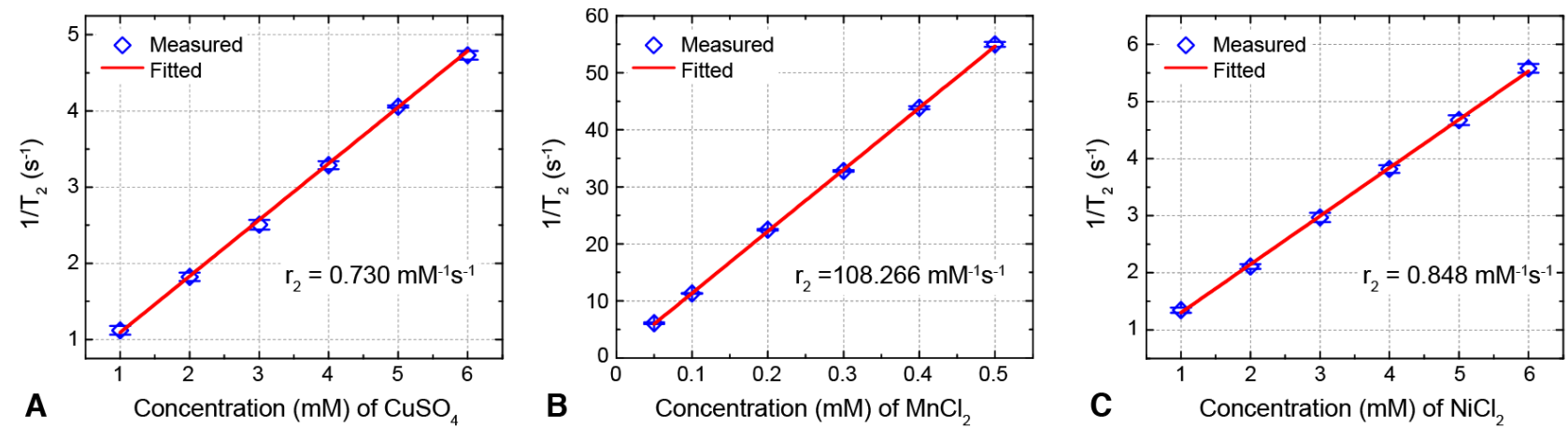

Figure 6. Transversal relaxation rates $\left(R_{2}=1 / T_{2}\right)$ as a function of concentration. The slopes of the fitted lines correspond to the $\mathrm{r}_{2}$ relaxivities: (A) $\mathrm{r}_{2}=0.730 \mathrm{mM}^{-1} \mathrm{~s}^{-1}$ for $\mathrm{CuSO}_{4}$, (B) $\mathrm{r}_{2}=108.266 \mathrm{mM}^{-1} \mathrm{~s}^{-1}$ for MnCl $\mathrm{Mn}_{2}$, and (C) $\mathrm{r}_{2}=0.848 \mathrm{mM}^{-1} \mathrm{~s}^{-1}$ for $\mathrm{NiCl}_{2}$. The error bars show the mean and standard deviations of the relaxation rates for each selected ROI at the given concentration (1214 \pm 124 pixels per ROI), and the solid red lines denote the linear least squares regressions with $\mathrm{r}^{2}>0.997$.

Table 2. The longitudinal relaxivity $\left(\mathrm{r}_{1}\right)$ and transversal relaxivity $\left(\mathrm{r}_{2}\right)$ for $\mathrm{CuSO}_{4}, \mathrm{MnCl}_{2}$, and $\mathrm{NiCl}_{2}$ measured at 3 $\mathrm{T}$, along with their $95 \%$ confidence intervals. While we provide $\mathrm{r}_{1}$ from both the two-parameter and the three-parameter models for the sake of completeness, the three-parameter model is more accurate. Hence, the last two columns are highlighted as the accurate $r_{1}$ and $r_{2}$ values for these paramagnetic agents.

\begin{tabular}{|l|l|l|l|}
\hline & $\begin{array}{l}\mathrm{r}_{1}\left(\mathrm{mM}^{-1} \mathrm{~s}^{-1}\right) \\
\text { 2-Parameter Model }\end{array}$ & $\begin{array}{l}\mathbf{r}_{1}\left(\mathbf{m M}^{-1} \mathbf{s}^{-1}\right) \\
\text { 3-Parameter Model }\end{array}$ & $\mathbf{r}_{2}\left(\mathbf{m M}^{-1} \mathbf{s}^{-1}\right)$ \\
\hline $\mathrm{CuSO}_{4}$ & $0.588(0.5881-0.5885)$ & $\mathbf{0 . 6 0 2}(\mathbf{0 . 6 0 1 9}-\mathbf{0 . 6 0 2 8})$ & $\mathbf{0 . 7 3 0}(\mathbf{0 . 7 2 8 5}-\mathbf{0 . 7 3 1 0})$ \\
\hline $\mathrm{MnCl}_{2}$ & $7.444(7.4375-7.4506)$ & $\mathbf{6 . 3 9 7}(\mathbf{6 . 3 9 0 3}-\mathbf{6 . 4 0 3 1})$ & $\mathbf{1 0 8 . 2 6 6 ( 1 0 8 . 2 1 9 3 - 1 0 8 . 3 1 2 6})$ \\
\hline $\mathrm{NiCl}_{2}$ & $0.609(0.6091-0.6096)$ & $\mathbf{0 . 6 2 0}(\mathbf{0 . 6 1 9 7}-\mathbf{0 . 6 2 0 6})$ & $\mathbf{0 . 8 4 8}(\mathbf{0 . 8 4 6 5}-\mathbf{0 . 8 4 8 8})$ \\
\hline
\end{tabular}


THANGAVEL and SARITAŞ/Turk J Elec Eng \& Comp Sci

Finally, the concentrations of $\mathrm{CuSO}_{4}, \mathrm{MnCl}_{2}$, and $\mathrm{NiCl}_{2}$ required to mimic the $\mathrm{T}_{1} / \mathrm{T}_{2}$ relaxation times of the basic tissue types such as gray matter, white matter, skeletal muscle, and blood at $3 \mathrm{~T}$ [33] have been determined and are shown in Table 3. Accordingly, $\mathrm{CuSO}_{4}$ and $\mathrm{NiCl}_{2}$ require significantly different concentrations for mimicking the $\mathrm{T}_{1}$ vs. the $\mathrm{T}_{2}$ of a given tissue. Hence, one can prepare either $\mathrm{T}_{1}$-mimicking phantoms or $\mathrm{T}_{2}$-mimicking phantoms with these agents, but not both. $\mathrm{MnCl}_{2}$, on the other hand, can closely match both the $\mathrm{T}_{1}$ and $\mathrm{T}_{2}$ of the listed tissues at approximately the same concentrations, and hence is a better choice for tissue mimicking phantoms.

Table 3. The concentrations of $\mathrm{CuSO}_{4}, \mathrm{MnCl}_{2}$, and $\mathrm{NiCl}_{2}$ required for achieving $\mathrm{T}_{1} / \mathrm{T}_{2}$ of basic tissue types such as gray matter, white matter, skeletal muscle, and blood along with the relaxation times of these tissues at $3 \mathrm{~T}$ [33] are shown. For example, approximately $0.03 \mathrm{mM}$ solution of $\mathrm{MnCl}_{2}$ closely mimics both the $\mathrm{T}_{1}$ and $\mathrm{T}_{2}$ relaxation times of blood.

\begin{tabular}{|l|l|l|l|l|}
\hline \multicolumn{2}{|c|}{} & $\mathrm{CuSO}_{4}(\mathrm{mM})$ & $\mathrm{MnCl}_{2}(\mathrm{mM})$ & $\mathrm{NiCl}_{2}(\mathrm{mM})$ \\
\hline \multirow{2}{*}{ Gray matter } & $\mathrm{T}_{1}=1820 \mathrm{~ms}$ & 0.468 & 0.036 & 0.394 \\
\cline { 2 - 5 } & $\mathrm{T}_{2}=99 \mathrm{~ms}$ & 13.341 & 0.088 & 11.387 \\
\hline \multirow{2}{*}{ White matter } & $\mathrm{T}_{1}=1084 \mathrm{~ms}$ & 1.087 & 0.094 & 0.995 \\
\cline { 2 - 5 } & $\mathrm{T}_{2}=69 \mathrm{~ms}$ & 19.359 & 0.128 & 16.568 \\
\hline \multirow{2}{*}{ Skeletal muscle } & $\mathrm{T}_{1}=1412 \mathrm{~ms}$ & 0.732 & 0.060 & 0.650 \\
\cline { 2 - 5 } & $\mathrm{T}_{2}=50 \mathrm{~ms}$ & 26.905 & 0.179 & 23.065 \\
\hline \multirow{2}{*}{ Blood } & $\mathrm{T}_{1}=1932 \mathrm{~ms}$ & 0.415 & 0.031 & 0.343 \\
\cline { 2 - 5 } & $\mathrm{T}_{2}=275 \mathrm{~ms}$ & 4.482 & 0.028 & 3.761 \\
\hline
\end{tabular}

\section{Discussion}

As seen in Table 2, the $\mathrm{r}_{1}$ relaxivities calculated using the two-parameter and the three-parameter models are similar, but do not match exactly. Specifically, the $\mathrm{r}_{1}$ values calculated using the two-parameter model are $1 \%^{-}$ $2 \%$ lower than those from the three-parameter model for $\mathrm{CuSO}_{4}$ and $\mathrm{NiCl}_{2}$. For $\mathrm{MnCl}_{2}$, on the other hand, the two-parameter model gave a $16 \%$ higher $\mathrm{r}_{1}$ value than the three-parameter model. We would like to note that the $\mathrm{r}_{1}$ relaxivity of $\mathrm{MnCl}_{2}$ at $3 \mathrm{~T}$ using the two-parameter model was previously reported as $7.4 \mathrm{mM}^{-1} \mathrm{~s}^{-1}$ by Nofiele and Cheng [25]. Our experiments were conducted in the same range of $\mathrm{MnCl}_{2}$ concentrations (up to $0.5 \mathrm{mM}$ ) as in Nofiele and Cheng's study, and our results agree perfectly when we also use the two-parameter model. Both the previous study and this work show that the $\mathrm{R}_{1}$ relaxation rate at $0.5 \mathrm{mM}$ displays increased standard deviation values or does not agree well with the fitted regression line. For the three-parameter model in Figure $5 \mathrm{~B}$, on the other hand, the $\mathrm{r}_{1}$ relaxivity provides a much better fit to the $1 / \mathrm{T}_{1}$ vs. concentration data points. As explained by Nofiele and Cheng, this difference could stem from the fact that the three-parameter model does not assume a perfect $180^{\circ}$ inversion pulse. Hence, in theory, whenever there is $\mathrm{B}_{1}$ inhomogeneity or any variation in the flip angle, the three-parameter model will provide more accurate results. Therefore, we highlight the results of the three-parameter model in Table 2.

The previously reported $\mathrm{r}_{2}=117 \mathrm{mM}^{-1} \mathrm{~s}^{-1}$ for $\mathrm{MnCl}_{2}$ [25] compares well with our result of $\mathrm{r}_{2}=$ $108 \mathrm{mM}^{-1} \mathrm{~s}^{-1}$ (approximately $8 \%$ difference). This relatively small difference may be due to differences in signal-to-noise ratios in the MRI images between the two studies. In addition, although the ranges of $\mathrm{MnCl}_{2}$ concentrations used in the two experiments match, the experiment in Nofiele and Cheng's study did not have any data points between $0.2 \mathrm{mM}$ and $0.5 \mathrm{mM}$. In such a case, small errors in measurement and/or fitting at 0.5 $\mathrm{mM}$ may cause deviations in the fitted slope, potentially leading to the difference observed here. 
THANGAVEL and SARITAŞ/Turk J Elec Eng \& Comp Sci

The relaxivities of the paramagnetic agents used in this work were previously reported at $1.5 \mathrm{~T}$. Accordingly, the relaxivity values $\left(\mathrm{r}_{1}, \mathrm{r}_{2}\right)$ in units of $\mathrm{mM}^{-1} \mathrm{~s}^{-1}$ were given as follows: for $\mathrm{Cu}^{2+}(0.69 \pm 0.04,0.77 \pm$ $0.04), \mathrm{Mn}^{2+}(7.0 \pm 0.4,70 \pm 4.0)$, and $\mathrm{Ni}^{2+}(0.7 \pm 0.06,0.7 \pm 0.06)$ [44-45]. Comparing these values with the relaxivities at $3 \mathrm{~T}$ reported in this work, $\mathrm{r}_{1}$ values are smaller and $\mathrm{r}_{2}$ values are either comparable or larger at $3 \mathrm{~T}$ than at $1.5 \mathrm{~T}$. This trend is consistent with previous works that list relaxivities at various field strengths for $\mathrm{MnCl}_{2}$ [46], gadolinium [22], and iron oxides [47]. It should be noted that the actual trend of relaxivity vs. field strength is not necessarily monotonous if one looks at a wider range of field strengths [2-5,48]. Hence, these results cannot be generalized.

The relaxivities $\left(\mathrm{r}_{1}, \mathrm{r}_{2}\right)$ in units of $\mathrm{mM}^{-1} \mathrm{~s}^{-1}$ for some of the clinically used gadolinium-based contrast agents were previously reported at $3 \mathrm{~T}$ : for Gadovist $(3.2 \pm 0.18,3.9 \pm 0.16)$, Omniscan (3.2 $\pm 0.18,3.3$ $\pm 0.16)$, and Gadomer $(13.0 \pm 0.1,23.0 \pm 0.04)[21]$. Comparing these values with the ones listed in Table 2, gadolinium-based agents have significantly higher relaxivites than $\mathrm{CuSO}_{4}$ and $\mathrm{NiCl}_{2}$. On the other hand, relaxivities of $\mathrm{MnCl}_{2}$ are comparable or higher than these clinical contrast agents, which is one of the reasons for the popularity of manganese-based contrast agents in preclinical research at $3 \mathrm{~T}$ and at higher field strengths $[23,26,27]$. It should be emphasized that the dosage of the manganese utilized in preclinical/clinical settings should be carefully adjusted to minimize the toxic side effects [49]. Accordingly, increasing the biocompatibility and relaxivity of manganese-based agents with different chelates/ligands is an active area of research [23,50].

\section{Conclusion}

We report the longitudinal $\left(\mathrm{r}_{1}\right)$ and transversal $\left(\mathrm{r}_{2}\right)$ relaxivities of $\mathrm{MnCl}_{2}, \mathrm{CuSO}_{4}$, and $\mathrm{NiCl}_{2}$ paramagnetic solutions at $3 \mathrm{~T}$. The relaxivities of these agents were previously reported at lower $\mathrm{B}_{0}$ field strengths, but a detailed study at $3 \mathrm{~T}$ was not available. These paramagnetic solutions are chemically and thermally stable, and their relaxation times are within the biological range. Hence, these paramagnetic agents are of practical importance when preparing MRI phantoms with desired $\mathrm{T}_{1}$ and $\mathrm{T}_{2}$ values for testing and/or calibrating various MRI sequences, especially for quantitative imaging methods.

\section{Acknowledgments}

The authors would like to thank Yıldıray Gökhalk for his help during the experiments, and Tolga Çukur and Ergin Atalar for their comments and suggestions on the manuscript. This work was supported by a TÜBİTAK 2216 Fellowship awarded to K. Thangavel. In addition, this work was supported by the Scientific and Technological Research Council of Turkey through TÜBİTAK Grants (114E167, ERA.Net RUS PLUS 215E198), by the European Commission through FP7 Marie Curie Career Integration Grants (PCIG13-GA2013-618834), by the Turkish Academy of Sciences through TÜBA-GEBIP 2015 program, and by the BAGEP Award of the Science Academy.

\section{References}

[1] Cheng HL, Stikov N, Ghugre NR, Wright GA. Practical medical applications of quantitative MR relaxometry. J Magn Reson Imaging 2012; 36: 805-824.

[2] Lartigue L, Oumzil K, Guari Y, Lartigue J, Guérin C, Montero JL, Barragan MV, Sangregorio C, Caneschi A, Innocenti $\mathrm{C}$ et al. Water soluble Rhamnose coated $\mathrm{Fe}_{3} \mathrm{O}_{4}$ nanoparticles. Org Lett 2009; 11: 2992-2995. 
THANGAVEL and SARITAŞ/Turk J Elec Eng \& Comp Sci

[3] Lartigue L, Innocenti C, Kalaivani T, Awwad A, Sanchez DM, Guari Y, Larionova J, Guérin C, Montero JLG, Barragan MV et al. Water-dispersible sugar coated magnetite nanoparticles. An evaluation of their relaxometric and magnetic hyperthermia properties. J Am Chem Soc 2011; 133: 10459-10472.

[4] Carniato F, Thangavel K, Tei L, Botta M. Structure and Dynamics of the Hydration shells of Citrate- coated GdF 3 Nanoparticles. J Mater Chem B 2013; 1: 2442-2446.

[5] Bordonali L, Kalaivani T, Sabareesh KPV, Innocenti C, Fantechi E, Sangregorio C, Casula MF, Lartigue L, Larionova J, Guari Y, et.al. NMR-D Study of the Local Spin dynamics and magnetic Anisotropy in different nearly monodispersed Ferrite nanoparticles. J Phys-Condens Mat 2013; 25: 066008(1)-066008(9).

[6] Price RR, Axel L, Morgan T, Newman R, Perman W, Schneiders N, Selikson M, Wood M, Thomas SR. Quality assurance methods and phantoms for magnetic resonance imaging: Report of AAPM nuclear magnetic resonance Task Group No.1. Med Phys 1990; 17: 287-295.

[7] Bucciolini M, Ciraolo L, Renzi R. Relaxation rates of paramagnetic solutions: evaluation by nuclear magnetic resonance imaging. Med Phys 1986; 13: 298-303.

[8] Schneiders NJ. Solutions of two paramagnetic ions for use in nuclear magnetic resonance phantoms. Med Phys 1988; 15: 12-16.

[9] Beall PT, Amtey SR, Kasturi SR. NMR Data Handbook for Biomedical Applications. New York, NY, USA: Pergamon Press, 1984.

[10] Pykett IL, Rosen BR, Buonanno FS, Brady TJ. Measurement of spin-lattice relaxation times in nuclear magnetic resonance imaging. Phys Med Biol 1983; 28: 723-729.

[11] Eunji I, Hani EN, Masoom H. Fabrication and characterization of polymer gel for MRI phantom with embedded lesion particles. P Soc Photo-Opt Ins 2012; 8348: 83480V(1)-83480V(12).

[12] Kato H, Kuroda M, Yoshimura K, Yoshida A, Hanamoto K, Kawasaki S, Shibuya K, Kanazawa S. Composition of MRI phantom equivalent to human tissues. Med Phys 2005; 32: 3199-3208.

[13] Korb JP, Bryant RG. Magnetic field dependence of proton spin-lattice relaxation times. Magn Reson Med 2002; 48: $21-26$.

[14] Sasaki M, Shibata E, Kanbara Y, Ehara S. Enhancement effects and relaxivities of gadolinium-DTPA at 1.5 versus 3 Tesla: a phantom study. Magn Reson Med Sci 2005; 4: 145-149.

[15] Jerrolds J, Keene S. MRI safety at 3 T versus 1.5 T. Internet J World Health Soc Politics 2008; 6: 1.

[16] Lawrence NT. 3 T MRI in clinical practice. Appl Radiol 2005; 34: 8-17.

[17] Trattnig S, Ba-Ssalamah A, Noebauer-Huhmann IM, Barth M, Wolfsberger S, Pinker K, Knosp E. MR Contrast agent at high-field MRI (3 Tesla). Top Magn Reson Imag 2003; 14: 365-375.

[18] Hattori K, Ikemoto Y, Takao W, Ohno S, Harimoto T, Kanazawa S, Oita M, Shibuya K, Kuroda M, Kato H. Development of MRI phantom equivalent to human tissues for 3.0-T MRI. Med Phys 2013; 40: 032303(1)$032303(11)$.

[19] Simon GH, Bauer J, Saborovski O, Fu Y, Corot C, Wendland MF, Daldrup-Link HE. T1 and T2 relaxivity of intracellular and extracellular USPIO at $1.5 \mathrm{~T}$ and $3 \mathrm{~T}$ clinical MR scanning. Eur Radiol 2006; 16: 738-745.

[20] Shen Y, Goerner FL, Snyder C, Morelli JN, Hao D, Hu D, Li X, Runge VM. T 1 relaxivities of gadolinium-based magnetic resonance contrast agents in human whole blood at 1.5, 3, and 7 T. Invest Radiol 2015; 50: 330-338.

[21] Rohrer M, Bauer H, Mintorovitch J, Requardt M, Weinmann HJ. Comparison of magnetic properties of MRI contrast media solutions at different magnetic field strengths. Invest Radiol 2005; 40: 715-724.

[22] Kalavagunta C, Metzger GJ. A field comparison of $\mathrm{r} 1$ and $\mathrm{r} 2 *$ relaxivities of Gd-DTPA in aqueous solution and whole blood: 3 T versus 7 T. Proc Int Soc Mag Reson Med 2010; 18: 4990.

[23] Pan D, Caruthers SD, Senpan A, Schmieder AH, Wickline SA, Lanza GM. Revisiting an old friend: manganesebased MRI contrast agents. WIREs Nanomed Nanobiotechnol 2011; 3: 162-173. 
THANGAVEL and SARITAŞ/Turk J Elec Eng \& Comp Sci

[24] Koylu MZ, Asubay S, Yilmaz A. Determination of proton relaxivities of $\mathrm{Mn}(\mathrm{II}), \mathrm{Cu}(\mathrm{II})$ and Cr(III) added to solutions of serum proteins. Molecules 2009; 14: 1537-1545.

[25] Nofiele JT, Cheng HL. Ultrashort echo time for improved positive-contrast manganese-enhanced MRI of cancer. Plos One 2013; 8: e58617(1)-e58617(8).

[26] Delattre BM, Braunersreuther V, Hyacinthe JN, Crowe LA, Mach F, Vallée JP. Myocardial infarction quantification with manganese-enhanced MRI (MEMRI) in mice using a 3 T clinical scanner. NMR Biomed 2010; 23: 503-513.

[27] Bilgen M. Imaging corticospinal tract connectivity in injured rat spinal cord using manganese-enhanced MRI. BMC Med Imaging 2006; 6: 15(1)-15(8).

[28] Stikov N, Boudreau M, Levesque IR, Tardif CL, Barral JK, Pike GB. On the accuracy of T 1 mapping: searching for common ground. Magn Reson Med 2014; 73: 514-522.

[29] Kingsley PB. Methods of measuring spin-lattice $\left(\mathrm{T}_{1}\right)$ relaxation times: an annotated bibliography. Concept Magnetic Res 1999; 11: 243-276.

[30] Bloembergen N, Purcell EM, Pound RV. Relaxation effects in nuclear magnetic resonance absorption. Phys Rev 1948; 73: 679-712.

[31] Frank LR, Wong EC, Buxton RB. Slice profile effects in adiabatic inversion: application to multislice perfusion imaging. Magn Reson Med 1997; 38: 558-564.

[32] Barral JK, Gudmundson E, Stikov N, Amoli ME, Stoica P, Nishimura D. A robust methodology for in vivo T 1 mapping. Magn Reson Med 2010; 64: 1057-1067.

[33] Stanisz GJ, Odrobina EE, Pun J, Escaravage M, Graham SJ, Bronskill MJ, Henkelman RM. T 1 , T 2 relaxation and magnetization transfer in tissue at 3 T. Magn Reson Med 2005; 54: 507-512.

[34] Sharma P, Socolow J, Patel S, Pettigrew RI, Oshinski JN. Effect of Gd-DTPA-BMA on blood and myocardial T 1 at $1.5 \mathrm{~T}$ and $3 \mathrm{~T}$ in humans. J Magn Reson Imaging 2006; 23: 323-330.

[35] Park JY, Baek MJ, Choi ES, Woo S, Kim JH, Kim TJ, Kim TJ, Jung JC, Chae KS, Chang Y, Lee GH. Paramagnetic ultrasmall gadolinium oxide nanoparticles as advanced T1 MRI contrast agent: account for large longitudinal relaxivity, optimal particle diameter, and in vivo T1 MR images. Acs Nano 2009; 3: 3663-3669.

[36] Aime S, Fedeli F, Sanino A, Terreno E. A R2/R1 ratiometric procedure for a concentration-independent, pHresponsive, Gd(III)-based MRI agent. J Am Chem Soc 2006; 128: 11326-11327.

[37] Pan D, Senpan A, Caruthers SD, Williams TA, Scott MJ, Gaffney PJ, Wickline SA, Lanza GM. Sensitive and efficient detection of thrombus with fibrin-specific manganese nanocolloids. Chem Commun 2009; 22: 3234-3236.

[38] Cukur T, Santos JM, Pauly JM, Nishimura DG. Variable-density parallel imaging with partially localized coil sensitivities. IEEE T Med Imaging 2010; 29: 1173-1181.

[39] Cukur T, Santos JM, Nishimura DG, Pauly JM. Varying kernel-extent gridding reconstruction for undersampled variable-density spirals. Magn Reson Med 2008; 59: 196-201.

[40] Bishop C. Pattern Recognition and Machine Learning. New York, NY, USA: Springer-Verlag, 2006.

[41] Vehtari A, Gelman A, Gabry J. Practical Bayesian model evaluation using leave-one-out cross-validation and WAIC. Arxiv 2016; 150704544v3.

[42] Rao CR, Wu Y. Linear model selection by cross-validation. J Stat Plan Infer 2005; 128: 231-240.

[43] Shao J. Linear model selection by cross-validation. J Am Stat Assoc 1993; 88: 486-494.

[44] Morgan LO, Nolle AW. Proton spin relaxation in aqueous solutions of paramagnetic ions. II. Cr,+++ Mn ++ , $\mathrm{Ni}++, \mathrm{Cu}++$, and $\mathrm{Gd}+++$. J Chem Phys 1959; 31: 365-368.

[45] Tofts PS. Quantitative MRI of the Brain: Measuring Changes Caused by Disease. West Sussex, UK: John Wiley \& Sons Ltd., 2003. 
THANGAVEL and SARITAŞ/Turk J Elec Eng \& Comp Sci

[46] Caravan P, Farrar CT, Frullano L, Uppal R. Influence of molecular parameters and increasing magnetic field strength on relaxivity of gadolinium- and manganese-based T1 contrast agents. Contrast Media Mol I 2009; 4: 89-100.

[47] Kostopoulou A, Velu SKP, Thangavel K, Orsini F, Brintakis K, Psycharakis S, Ranella A, Bordonali L, Lappas A, Lascialfari A. Colloidal assemblies of oriented maghemite nanocrystals and their NMR relaxometric properties. Dalton T 2014; 43: 8395-8404.

[48] Roch A, Muller RN, Gillis P. Theory of proton relaxation induced by superparamagnetic particles. J Chem Phys 1999; 110: 5403-5411.

[49] Silva AC, Bock NA. Manganese-enhanced MRI: an exceptional tool in translational neuroimaging. Schizophrenia Bull 2008; 34: 595-604.

[50] Pan D, Schmieder AH, Wickline SA, Lanza GM. Manganese-based MRI contrast agents: past, present, and future. Tetrahedron 2011; 67: 8431-8444. 